\title{
STRATEGIES FOR STUDYING PERMEATION AT VOLTAGE-GATED ION CHANNELS
}

\author{
Henry A. Lester \\ Division of Biology, California Institute of Technology, Pasadena California 91125 \\ KEY WORDS: heterologous expression, sodium/potassium/calcium channel excitable mem- \\ branes, local anesthetics, site-directed mutagenesis
}

\section{INTRODUCTION}

Voltage-dependent ion channels are presently thought to consist of several distinct functional regions: $(a)$ activation gates, $(b)$ inactivation gates, and $(c)$ permeation pathways. This chapter focuses on permeation pathways and may spur new ideas about experiments that use site-directed mutagenesis to probe the ion conduction pathway. Some hubris is required to attempt a survey of this field since individual families-- $\mathrm{K}^{+}, \mathrm{Na}^{+}$, or $\mathrm{Ca}^{2+}$ - have been reviewed in detail $(15,68,115,127)$. My unified treatment is motivated by the structural similarity suggested by recent cDNA sequencing data on this group (see, for instance, 24). There have been many excellent previous treatments of ion channel permeation $(6,15,34,35,51,53,68,73,74,115,127)$.

Most well-characterized voltage-dependent channels in animal cells are selective for cations and, as a class, these channels are more selective than the ligand-gated cation channels of postsynaptic membranes. At present there are few reports of pharmacological or genetic manipulations that affect the selectivity of ion channels, e.g. that change $\mathrm{Na}^{+}$to $\mathrm{K}^{+}$or $\mathrm{Ca}^{2+}$ channels. When successfully performed and interpreted, such manipulations will represent a triumph of the site-directed mutagenesis approach. It is already known that batrachotoxin and aconitine render $\mathrm{Na}^{+}$channels less selective for $\mathrm{Na}^{+}$than for many other ions (62). 


\section{LESTER}

\section{A View of Permeation and Selectivity}

I invoke the reviewer's privilege and responsibility to offer, before summarizing all the facts, a unified hypothesis for permeation and selectivity that emerges from much of the work discussed below (and that is explicitly stated in some of the papers). The problem is that high selectivity generally occurs via high-affinity binding, which in turn implies long-lived complexes, which are incompatible with high flux rates through a channel. For instance, if an ion bound with an apparent dissociation constant of $10 \mu \mathrm{M}$ or less (95) at a diffusion-limited forward binding rate of $10^{9} \mathrm{M}^{-1} \mathrm{~s}^{-1}$, it would remain bound for $100 \mu \mathrm{s}$ or more, at least 1,000 times too long to account for the flux through most channels. An escape from this quandary is offered by the fact that the concentrations of ions are so high that their chemical potential also drives other less favorable processes, in this case mutual repulsion among bound ions in the channel. Channels appear to have a series of binding sites that, when unoccupied, have high affinity for the permeant ion (and much lower affinity for impermeant ones). When one such site is occupied, however, the affinity of neighboring sites decreases by several orders of magnitude, presumably because of electrostatic interactions among bound ions. Nonetheless, the high concentration of the permeant ion assures that neighboring sites are often simultaneously occupied. The brief residence times associated with the low affinity assure that ions hop rapidly among binding sites; the electrochemical driving force assures that the hops are predominantly in the direction of current flow. Recent modeling, involving Eyring rate theory and the concepts summarized above, provides a quantitative explanation for the process at $\mathrm{Ca}^{2+}$ channels (40). Similar analyses are available for a highconductance $\mathrm{Ca}^{2+}$-activated $\mathrm{K}$ channel $(94,95)$. It should be noted that different $\mathrm{K}^{+}$channels vary substantially in their permeation characteristics (127) and also that $\mathrm{Na}^{+}$channels may not normally function with multisite binding.

Several classes of measurement are available to count, localize, and define the binding sites in the permeation pathway. I summarize these measurements and the available results below.

\section{Reversal Potentials}

The use of reversal potentials to measure selectivity has been developed, applied experimentally, and reviewed by Hille (53), and will not be treated exhaustively here. A relative permeability $P_{B} / P_{A}$ is obtained from measurements of the shift in reversal potential, $\Delta E_{\text {rev }}=(R T / z F) \ln \left(P_{\mathrm{B}}[B]_{\mathrm{o}} / P_{\mathrm{A}}[A]_{\mathrm{o}}\right)$, when cation $A$ is replaced by cation $B$, both of valence $z$, in the external solution. What is the physical meaning of the result? Formally, the permeability coefficient $P$ for an ion is a bulk property proportional to the watermembrane partition coefficient and to the diffusion coefficient within the 
membrane. In Eyring rate theory, a particle hops over energy barriers as it diffuses; the diffusion coefficient is proportional to a hopping frequency that decreases exponentially with the height of the barrier. Therefore, in the usual interpretation, permeability is dominated by the highest energy barrier that an ion must traverse in crossing the membrane. Because permeabilities measured in this way often seem to decrease monotonically with hydrated radius or other measures of molecular size, the critical energy barrier is usually identified with the narrowest region of the channel. This interpretation has given rise to many of the analyses that deduce the diameter of the selectivity filter based on the relative permeabilities for different ions. The reversal potential measurement is widely applicable because it is sensitive to neither block nor saturation in the channel. This insensitivity, however, also shows the limitations of reversal potential measurements for revealing details of the permeation process.

\section{Current-Voltage Relations}

THE MEANING OF RECTIFICATION In recent experiments on both acetylcholine receptors $(58,71)$ and $K$ channels $(81)$, some mutations have introduced rectification in the single-channel current-voltage (I-V) relation. Rectification allows one to deduce the approximate location of a new energy barrier (Figure 1). The additional energy barrier could be a narrow region, a change in dipole moment, or a change in charge-in general, something that makes ions pause as they move through the channel. If the barrier is sharp with a height $\Delta \mathrm{G}^{+}$, then the rate constant for crossing the barrier is $k k T /$ $h\left[\exp \left(-\Delta \mathrm{G}^{+} / R T\right)\right]$. The reflection coefficient $\kappa(0<\kappa<1)$ is unknown, but presumably it applies to a similarly shaped barrier anywhere along the channel.

The effect of this new barrier depends on its location. As shown in Figure 1 , the new barrier is at an electrical distance $\delta$ from the extracellular surface of the membrane $(0<\delta<1 ; \delta=1$ corresponds to the cytoplasmic surface). Ions experience an energy difference $z q \delta \mathrm{V}$ between the base of the barrier and the external solution, where $q$ is the elemental charge. This energy difference tends to accumulate ions at the extracellular-facing base of the barrier, relative to the extracellular solution, by the Boltzmann factor $\exp (-z q \delta \mathrm{V} / k T)$. If $\mathrm{V}$ is $-100 \mathrm{mV}, z q=+1$ electronic charge, and the barrier is located $\delta=2 / 3$ of the distance to the intracellular face, then the accumulation is by a factor of 15 . Now consider the case for an ion entering from the cytoplasmic face and driven in the opposite direction by the voltage gradient. In this case, the appropriate expression uses $\delta=1 / 3$, and the accumulation at the intracellular base of the barrier is by only a factor of 3.7. Thus a new barrier, if located asymmetrically, can be overcome more easily by current in one direction. The 

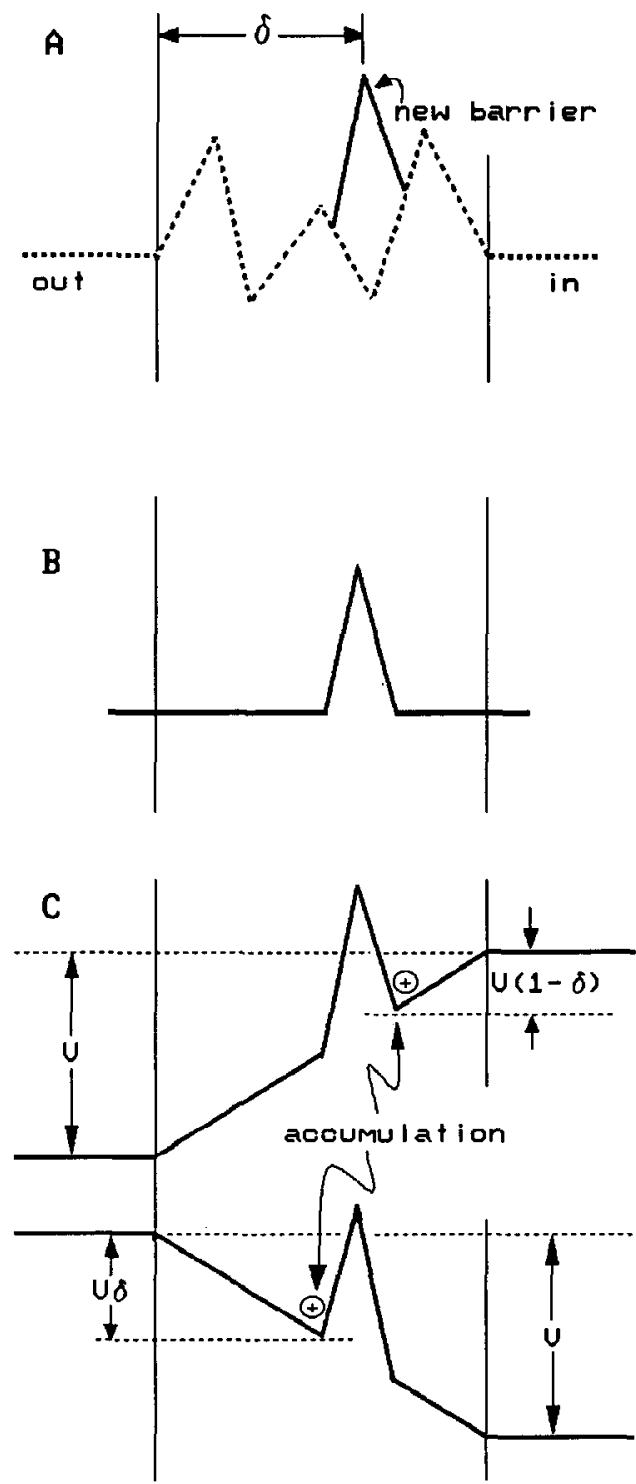

Figure I A diagram showing the energy experienced by an ion in a channel as a function of the distance (horizontal axis). In $(A)$ the normal channel is characterized by the dashed line; and a mutation introduces a localized extra barrier (solid line). In $(B)$ the extra barrier is shown in isolation for simpler analysis. $(C)$ shows how the energy of the ion at the new barrier, relative to that in the solutions, is changed when a voltage is applied across the membrane. We assume here and in all figures $(a)$ that the field in the membrane is constant and $(b)$ that the barrier is so thin that the peak and bases are all roughly at the position $\delta$. 
resulting change in the current-voltage relation is diagnostic for the location of the new energy barrier.

SURFACE-CHARGE EFFECTS ON CURRENT-VOLTAGE RELATIONS Operationally, surface charge effects are suspected when all divalent cations (or higher concentrations of monovalent cations) produce a roughly equal concentration-dependent shift in a voltage-dependent parameter (85). The perturbation of the energy profile produced by surface charge differs from that produced by an energy barrier as discussed above: the potential well is $(a)$ eccentric-confined to one surface of the membrane, and $(b)$ asymmetricthere is a steep change in the solution near the membrane and a gradual one within the membrane (Figure 2). In the usual situation, substantial negative surface potential at the outer surface of the membrane tends to accumulate cations within one Debye length of the membrane. If this increased concentration occurs near a barrier that is rate-limiting for permeation (as in Figure 2),
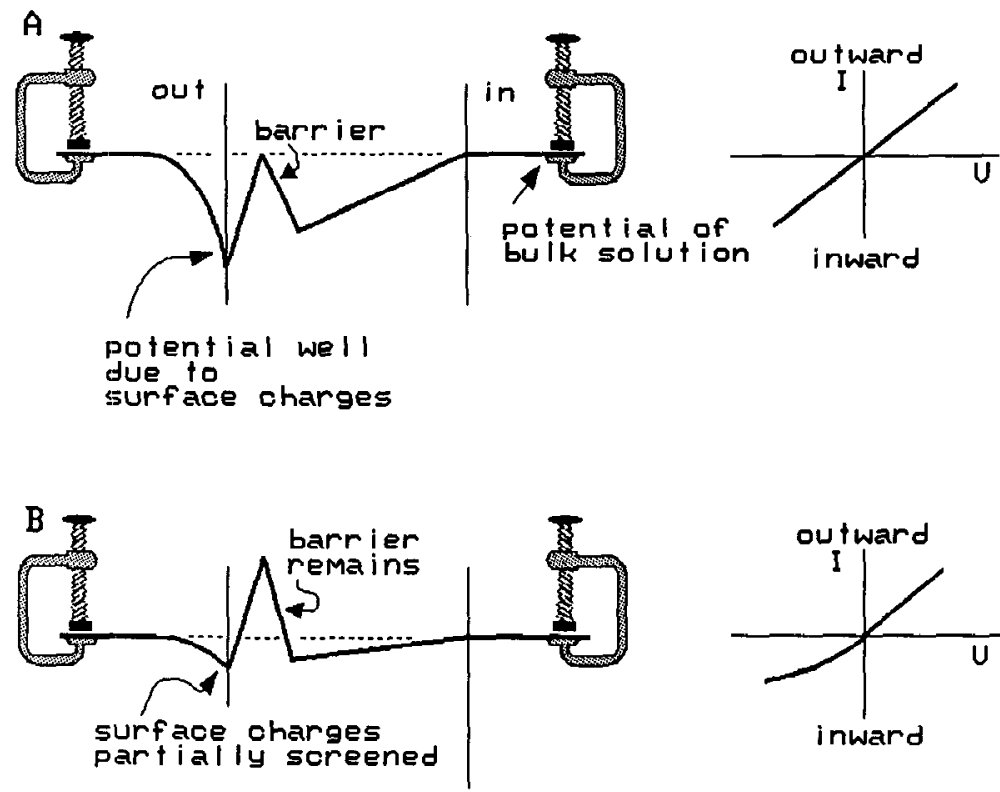

Figure 2 (A) This channel has two features. (a) It has a negative surface potential. In the external solution, this potential decreases to zero roughly within the Debye length ( $\sim 8 \AA$ ). In the membrane, the potential gradient is much less. More than a few $\mathrm{nm}$ from the membrane, the potential is unaffected by the surface potential and is clamped to the value in the bulk solution. (b) The channel has an asymmetrically located energy barrier like the one in Figure 1. (B) Reduction of the surface potential cannot be directly detected by electrodes in the bulk solution. This change, however, allows the energy barrier to influence ion permeation more strongly, as in Figure 1. 
increased current flow results. As another result of surface charge accumulation, the relation between zero-voltage channel conductance and permeant cation concentration shows a non-zero intercept as the ionic strength is lowered symmetrically $(7,16,77,89)$.

The typical experimental manipulation involving increased external divalent ion concentration leads to screening of negative surface charge and would therefore decrease inward current flow. For instance, in the study by Green et al (43), in the absence of divalent cations, reconstituted $\mathrm{Na}^{+}$ channels showed a linear current-voltage relation. When $\mathrm{Ba}^{2+}$ was added to the external solution, the conductance decreased substantially more for inward than for outward currents. For $\mathrm{K}^{+}$channel mutants with threonine-449 replaced by lysine, arginine, or glutamine in an extracellular region, the reduction in external negative surface charge again leads to a greater decrease in inward than outward current (81). There is also some evidence for surface charge at the cytoplasmic face of the Na channels (105a).

Another manipulation of surface charge is based on the fact that $\mathrm{Na}^{+}$ channels seem to contain a carboxylate group that can be esterified by trimethyloxonium (TMO) and other reagents $(26,105,106,123)$. Highconductance $\mathrm{Ca}^{2+}$-activated $\mathrm{K}^{+}$channels have several such groups $(77,80)$. The esterification reduces currents.

Phospholipid head groups probably do not contribute significantly to the surface potential of channels. The negative surface potential might arise from aspartate or glutamate residues; it might also arise from sugars bearing carboxylate, phosphate, or sulfate groups. Most intrinsic plasma membrane proteins are glycosylated on their extracellular faces. All known subunits of electrically excitable $\mathrm{Na}^{+}$and $\mathrm{Ca}^{2+}$ channels, except for the $\alpha 1$ and $\beta$ subunits of the skeletal muscle $\mathrm{Ca}^{2+}$ channel, are glycosylated to a level of $20-40 \%$ by weight. The dominant acidic sugar in the $\alpha$ subunit of $\mathrm{Na}^{+}$channels is sialic acid in many (60), but not all (42), cases.

\section{Anomalous Mole-Fraction Effects}

For a channel with a unique saturable binding site, single-channel currents for mixtures of permeant ions could be described as the weighted sum (according to the mole fraction) of the current due to each individual ion: if ions $A$ and $B$, at a total concentration of $C_{t}$, are characterized by single-channel currents $i_{A}$ and $\mathrm{i}_{B}$, then the current in a solution of $[A]+[B]=C_{\mathrm{t}}$ and $[A] / C_{\mathrm{t}}=\mu_{A}$ is $\mathrm{i}=$ $\mathrm{i}_{A} \mu_{A}+\mathrm{i}_{B}\left(1-\mu_{A}\right)$. For $\mathrm{Ca}^{2+}$ channels $(4,19,41,50,84)$ and for some $\mathrm{K}^{+}$ channels $(36,48)$, on the other hand, currents go through a minimum as $\mu_{A}$ is varied. Recent studies confirm this anomalous mole-fraction effect at the single-channel level $(28,36,40)$; it is not restricted to voltage-dependent cation channels. Although there are alternative explanations involving 
allosteric effects $(22,63,64,88)$, the most commonly accepted explanation is that the permeant ions are interacting within the lumen of a single-file pore.

The anomalous mole-fraction effect exists, like the frank blockade described in the next section, when one ionic species occupies the channel and prevents another from permeating it. The interaction between the two ions is expected to depend on the electrochemical driving force for occupancy of the sites within the channel. In particular, for a given extramembrane concentration of $[A]$, the saturation of a binding site also depends on the Boltzmann factor given above, in which membrane potential plays a role. Thus, the presence of an observable anomalous mole-fraction effect is also expected to depend on the membrane potential $(21,40)$. Theoretical modeling of these effects yields good agreement with the data if there are two, or perhaps three, (see 82) binding sites for permeant ions within the $\mathrm{Ca}^{2+}$ channel. For $\mathrm{K}^{+}$ channels, there clearly are at least two sites and probably more.

$\mathrm{Na}^{+}$channels are generally thought not to exhibit anomalous mole-fraction effects, and there appear to be few interactions among permeant ions within the batrachotoxin-modified channels that are studied with bilayer reconstitution (e.g. reference 43). As pointed out by Hille (53), however, anomalous mole-fraction effects may occur only at extremes of concentration that do not allow the appropriate measurements. It is clear, nonetheless, that permeability ratios $P_{\mathrm{K}} / P_{\mathrm{Na}}$ and $P_{\mathrm{NH} 4} / P_{\mathrm{Na}}$ decrease as the intracellular $\mathrm{K}^{+}$and $\mathrm{NH}_{4}$ concentrations increase, as though the $\mathrm{Na}^{+}$channel can hold at least two ions simultaneously (15a). This fact is also revealed by experiments cited below on blockade by inorganic ions (reviewed in reference 15 ). Thus all voltagedependent cation channels probably have at least two ion-binding sites. Are they at similar points in either the primary sequence or the three-dimensional structure?

\section{Blockade within the Channel by Inorganic Ions}

Evidence for mutually interacting binding sites also comes from analysis of inorganic blocking ions. One description is that the blocking ion is very slightly permeant. It visits some or all of the same sites that the normally permeant ion visits, but it remains at these sites so long that normally permeant ions are excluded from them (67).

A key concept in the view of such effects is the fact that blockade has vastly different signatures in single-channel records, depending on the time scale of blockade $(53,125,126)$. A ligand that binds tightly at equilibrium $\left(K_{\mathrm{D}}\right.$ rather small) often does so because its rate constant $k_{-}$for dissociation is quite slow $\left(K_{\mathrm{D}}=k_{-} / k_{+}\right)$. A reasonable rate constant for inorganic ion binding, $10^{9}$ $\mathrm{M}^{-1} \mathrm{~s}^{-1}$, implies that a blocker whose $K_{\mathrm{D}}$ is $1 \mu \mathrm{M}$ has an average lifetime $1 / k_{-}$of $1 \mathrm{~ms}$. Lifetimes one hundred times greater than this would have kinetics that are not easily distinguished from those of the channel gating; 
lifetimes one hundred times less than this would be so brief that they appear to decrease single-channel current rather than produce observable flickers.

How does one know that the blocking ion is (a) physically blocking the conduction pathway rather than $(b)$ binding elsewhere on the channel protein to change gating or permeation mechanism (as apparently occurs for proton block of $\mathrm{Ca}^{2+}$ channels; references 100,101$)$ ? The conclusion that a blocker binds within the conduction pathway is presently based on circumstantial rather than direct structural evidence. For instance, the rate constant for termination of the open channel is increased by the amount $[I] k_{+}$, where $[I]$ is the blocking ion concentration, and this relationship holds at the highest [I] observable (a plateau in the rate could imply an indirect binding of the ion that changes gating kinetics). In some special cases, it is possible to show that the channel must be in its open conformation to allow the blocker to bind or dissociate (87). The blocked time $1 / \mathrm{k} /$, does not change with concentration. The blocking kinetics or equilibrium blockade depend on voltage, which suggests that the blocker binds within the membrane field.

The voltage dependence of blockade is informative when inorganic ions are used to probe the conduction pathway (121). The analysis can proceed by invoking the same voltage-dependent Boltzmann factor described above. Alternatively, the equilibrium dissociation constant $K_{\mathrm{D}}$ for the blockerchannel binding is determined by the free energy change $\Delta \mathrm{G}^{+}$bound $-\Delta \mathrm{G}^{+}$free between the solution and the binding site. One term in this energy comes from the interaction between the field in the membrane and the charge on the ion and equals $z q \delta \mathrm{V}$. The relationship between free energy change and equilibrium binding affinity thus implies that the affinity is changed by the factor $\exp (-z q \delta \mathrm{V} / k T)$. Thus, if a monovalent blocking ion binds halfway through the membrane field and can leave only via the route of entry (the channel tapers past the binding site), one expects the equilibrium affinity for binding to vary by $e$-fold for each $12.5 \mathrm{mV}$ change in potential (at $300^{\circ} \mathrm{K}, k T=25$ $\mathrm{meV}$ ). If the voltage dependence is greater than $e$-fold per $25 \mathrm{mV}$, this is good evidence for a more complex mechanism (25). If the blocking ion can actually leave the site by continuing through the membrane, then the analysis may be complicated by the existence of an additional rate-limiting step (121).

Single-channel measurements have proven particularly useful for understanding the blockade of $\mathrm{Ca}^{2+}$ channels by inorganic ions $(83,93)$. Lansman \& colleagues $(66,67,120)$ have conducted a series of experiments on the blockade of current through single-ion channels by $\mathrm{Cd}^{2+}, \mathrm{Mg}^{2+}$, $\mathrm{Ca}^{2+}$, by trivalent lanthanides $\left(\mathrm{La}^{3+}, \mathrm{Nd}^{3+}, \mathrm{Gd}^{3+}, \mathrm{Dy}^{3+}\right.$, and $\left.\mathrm{Yb}^{3+}\right)$, and by divalent transition metals $\left(\mathrm{Zn}^{2+}, \mathrm{Fe}^{2+}, \mathrm{Co}^{2+}\right.$, and $\left.\mathrm{Ni}^{2+}\right)$. The trivalent lanthanides provide a convenient series of ions with graded radii, coordination numbers similar to $\mathrm{Ca}^{2+}$, and similar preferences for binding to oxygen donor groups. As the unhydrated radius decreases (from $1.16 \AA$ for $\mathrm{La}^{3+}$ to $0.99 \AA$ for $\mathrm{Yb}^{3+}$ ), the forward rate constant for blocking decreases by 20 -fold. 
Because the entry rate does not depend on voltage, Lansman suggests that an energy barrier within the membrane is not the rate-limiting step in binding. Instead, the rate-limiting step may be dehydration, whose rate decreases with radius in the lanthanide series (32). The lifetime of the ion at its binding site increases for smaller ions, but seems to approach a maximum for ions of radius equal to or smaller than $\mathrm{Ca}^{2+}$. These results show that the binding site is likely to be different in structure from the simplest model, EGTA, and to involve interactions distinct from electrostatic interactions based on size.

Another observation that supports the picture of a blocker occluding the actual conduction pathway is trans-enhanced dissociation (78); the blocker competes for its binding site with permeant ions added from the opposite side of the membrane. Trans-enhanced dissociation has been observed for $\mathrm{K}^{+}$ channels with several blocking ions including $\mathrm{Cs}^{+}(1,18), \mathrm{Na}^{+}(125,126)$, and $\mathrm{Ba}^{2+}$ (117), as well as for $\mathrm{H}^{+}$blockade of $\mathrm{Na}^{+}$channels (15b).

A thorough series of experiments on blockade by inorganic ions has utilized $\mathrm{Ba}^{2+}$ at $\mathrm{K}^{+}$channels $(13,14,17,33,87,94,95,117) . \mathrm{Ba}^{2+}$ can leave the channel either to the internal or the external solution. The particular favored direction depends on several factors, including the membrane potential and the concentration of permeant ions on either side of the membrane. The latter effect occurs because of a complement to the trans-enhanced dissociation effect. It is most obvious in $\mathrm{K}^{+}$channels because they usually hold several permeant ions at once. By occupying sites that the blocking ion must visit in order to leave the channel (and thereby relieve the block), the permeant ions exert a cis-suppressed dissociation (called lock-in by Neyton \& Miller, 94). Findings of this sort should be distinguished from the effects of the ions on the gating equilibria $(13,94)$. Because the high-conductance $\mathrm{K}^{+}$channel allows measurements over a wide range of ionic conditions, it is possible to investigate the concentration- and voltage-dependence of cis-suppressed dissociation. The conclusion is that at least three permeant ions, in addition to a blocking ion, can occupy the channel simultaneously.

At $\mathrm{Na}^{+}$channels, inorganic blockers reveal the existence of at least two binding sites, for such blockers have different effects when added from different sides of the membrane $(43,65,102)$. The site accessible from the external solution seems to lie within the membrane field. Recent studies suggest that $\mathrm{Mg}^{2+}$ can reach this site from the intracellular solution as well (102). In some studies the internal site seems to be outside the field and may be near the binding site for the inactivation gate; in other studies $(15 \mathrm{a}, \mathrm{b})$, a voltage-dependent site is also accessible from the internal solution.

\section{Blockade within the Channel by Organic Ions and Local Anesthetics}

Tertiary and quaternary ammonium ions have diameters (4-8 $\AA$ ) similar to those of hydrated cations. The clinically useful local anesthetics, which are 


\section{LESTER}

mostly tertiary amines, are not the molecules of choice for mapping out permeation pathways. Terms such as the modulated receptor $(52,55)$ and the guarded receptor (110) emphasize that these drugs can reach their binding sites via at least two pathways-the external solution and the membrane-and when the channel is in several distinct states $(52,54)$.

Quaternary ammonium derivatives of these molecules, on the other hand, constitute excellent probes of open channels. They typically reach a blocking site on the cytoplasmic face of $\mathrm{a} \mathrm{Na}^{+}$and $\mathrm{K}^{+}$channel only when the channel is open, like a plug in a drain $(8,11,38)$. These channel blockers are characterized by many of the phenomena that apply to inorganic blockers. Their binding is voltage-dependent, often more strongly with divalent than with monovalent blockers $(30,86,118)$. Their binding kinetics depend linearly and simply on the concentration; they exhibit trans-enhanced dissociation at both $\mathrm{K}^{+}(9,78)$ and $\mathrm{Na}^{+}(20,104)$ channels. On the other hand, the quaternary ammonium blocking ions themselves typically can reach their binding sites from only one side of the membrane and are totally impermeant. Series of related quaternary ammonium blocking compounds have traditionally been used in a pharmacological approach to mapping out the permeation pathway. Site-directed mutagenesis will enable "reverse pharmacology" in which the channel itself is modified while just one or a few compounds are studied.

$\mathrm{K}^{+}$CHANNELS One promising site for such studies is the cytoplasmic surface of $\mathrm{K}^{+}$channels. The existing data with various mono- and bisquaternary ammonium derivatives indicate that this inner mouth may be about $12 \AA$ in diameter for the squid axon delayed rectifier $(38,39), \mathrm{K}^{+}$channel from sarcoplasmic reticulum (86), and a $\mathrm{Ca}^{2+}$-activated $\mathrm{K}^{+}$channel from $\mathrm{T}$ tubules (118).

Externally applied tetraethylammonium (TEA) blocks almost all $\mathrm{K}^{+}$channels much more strongly than do other quaternary ammonium ions (see, for instance, 118). Nonetheless $\mathrm{K}^{+}$channels display a wide spectrum of affinities for this blockade. The first fruits of reverse pharmacology are ripening. MacKinnon \& Yellen (81) suggest, on the basis of site-directed mutagenesis on the S5-S6 loop of Shaker channels, that a single threonine side chain governs a substantial portion of this variability within the class of channels homologous to Shaker. Channels in which threonine is replaced by tyrosine, lysine, arginine, or asparagine at a particular position lack a high-affinity blockade by external TEA. The result recalls the important role played by hydroxyl-containing residues in the binding site for quaternary ammonium open-channel blockers at the nicotinic receptor $(27,71)$.

Most $\mathrm{K}^{+}$channels can close even while blocked by external TEA (31, 107-109). The exception is an inactivating, voltage-dependent $\mathrm{K}^{+}$channel of 
human lymphocytes (45). For this channel, TEA appears to act as a pure open-channel blocker: the channel cannot close when the blocker is bound. Furthermore, the blocker cannot bind to closed channels, i.e. there is no closed-blocked state. This interaction between the gates and a channel blocker gives rise to fascinating kinetic properties. At the single-channel level, the sum of all the open intervals remains constant. Single openings in the blocker's absence become lengthier bursts of openings in the blocker's presence. At the macroscopic level, relaxations are lengthened. The quantitative analysis of such kinetic effects provides a sensitive assay for the blockerchannel interaction $(27,71)$.

$\mathrm{Na}^{+}$CHANNELS The best studied quaternary ammonium channel blocker of $\mathrm{Na}^{+}$channels is QX-314 $(37,111$; but see 29$)$. Hille (53) has pointed out the distinction between smaller organic $\mathrm{Na}^{+}$channel blockers, such as QX-314, that allow gating to proceed, if with altered rates, and those so large $[\mathrm{N}$ methylstrychnine, pancuronium, and thiazin dyes $(12,20,104,124)]$ that their presence within the channel completely hinders the operation of the gates. In a reverse pharmacological approach to $\mathrm{Na}^{+}$channel structure, I suggest the use of channels mutated or broken into two chains to eliminate inactivation, probed with one small blocker, such as QX-314, and with one large blocker, such as $\mathrm{N}$-methylstrychnine.

$\mathrm{Ca}^{+}$CHANNELS The clinically useful organic $\mathrm{Ca}^{2+}$ channel blockers, like the local anesthetics, were designed to reach their receptors from the extracellular solution and to interact with both open and inactivated states of the channel. For a pharmacologically simple probe of the open $\mathrm{Ca}^{2+}$ channel, one should again turn to quaternary ammonium analogues, for instance the verapamil derivative $\mathrm{D}-890$. This compound blocks open $\mathrm{Ca}^{2+}$ channels on the cytoplasmic surface analogously to the way quaternary ammonium ions block open $\mathrm{Na}^{+}$and $\mathrm{K}^{+}$channels $(49,70,99)$.

\section{Blockade by Guanidinium and Peptide Toxins}

Electrically excitable $\mathrm{Na}^{+}$channels have several partially distinct binding sites for peptide toxins, lipid soluble toxins, and guanidinium toxins (23, 112). None of these sites is thought to lie within the permeation pathway. Interestingly, however, site-directed monoclonal antibodies and site-directed mutants have revealed that the binding sites for two of the best-characterized toxins, scorpion toxin and tetrodotoxin, are partially on the putative extracellular loop between the S5 and S6 membrane-spanning domains (96, 114). Extracellular blockade of neuronal $\mathrm{Na}^{+}$channels by tetrodotoxin (TTX) is voltage-dependent only for the case of channels modified by batrachotoxin, but this voltage dependence is thought to arise from a conformational change 
rather than from binding within the channel $(43,91,122)$. Yet many workers think that TTX binds at the extracellular mouth of the channel (90). Evidence for this view is the similarity between the properties of $\mathrm{Na}^{+}$channels that are $O$-methylated by trimethyloxonium and those that are naturally resistant to TTX. Both have reduced single-channel conductance and reduced sensitivity to open-channel block by extracellular $\mathrm{Ca}^{2+}(105,106,119,123)$. Conversely, the toxins and $\mathrm{Ca}^{2+}$ both protect against $O$-methylation (123). Single-hit kinetics with TMO suggest that a single carboxylate group is involved (but see 26). This may be glutamate-387 since the E387Q mutation decreases TTX sensitivity by $\sim 10^{3}(96)$. The mutant has altered macroscopic currentvoltage properties; however, single-channel conductances were not reported.

It now appears that the region where charybdotoxin (CTX) binds to some $\mathrm{K}^{+}$channels is homologous to the region where TTX binds to the $\mathrm{Na}^{+}$ channel $(76,79,96)$. The evidence favors the view that this interaction occurs at the extracellular mouth of the channel and that charybdotoxin is physically plugging the channel, like the simpler local anesthetics described above. The interaction between charybdotoxin and a high-conductance $\mathrm{Ca}^{2+}$-activated $\mathrm{K}^{+}$channel is well-described by a simple bimolecular binding; the association rate is sevenfold faster for the open than for the closed channel (5). Furthermore, the dissociation rate constant is increased as the intracellular concentration of permeant ions $\left(\mathrm{K}^{+}\right.$or $\left.\mathrm{Rb}^{+}\right)$, but not of impermeant ions $\left(\mathrm{Na}^{+}, \mathrm{Li}^{+}\right.$, $\mathrm{Cs}^{+}$, or arginine) is increased. This acceleration of dissociation is enhanced by membrane depolarization at a rate of $e$-fold $/ 28 \mathrm{mV}$, as though the field is concentrating the permeant ions at a site near the extracellular mouth of the channel where they compete with charybdotoxin binding. TEA, which blocks the pore from the external solution, competitively prevents the binding of CTX at the Shaker $\mathrm{K}^{+}$channels (C. Miller, R. MacKinnon, personal communication). These facts motivated the site-directed mutagenesis experiments of MacKinnon \& colleagues $(76,79,81)$, which located the region between the S5 and S6 loops as part of the binding site for charybdotoxin.

At the risk of simplifying the structural picture too greatly, I therefore suggest that all the available evidence points to the loop between helices 5 and 6 as part of the extracellular binding site for toxins at two well-understood channels, $\mathrm{Na}^{+}$and $\mathrm{K}^{+}$, and that these regions are quite close to the conduction pathway itself. These data do not yet bear directly on the hypothesis ( 44 , $46,47)$ that the channel protein crosses the membrane twice, perhaps with $\beta$ strands, in this region. The loop between helices S5 and S6 has not yet been explored for $\mathrm{Ca}^{2+}$ channels.

\section{Blockade by the Inactivation Flap}

It has long been known that $\mathrm{Na}^{+}$channels have an intracellular region where proteolysis removes inactivation. This helped motivate the ball-and-chain model for inactivation (10) in which a part of the channel protein actually 
occludes ion flow through the open channel. I prefer the term flap to describe this region. If this model is correct, then the receptor for the flap is at the intracellular mouth of the channel. Because inactivation has little or no voltage dependence, the receptive region may lie only a small fraction of the way through the field (3).

The flap itself has been tentatively identified and seems to consist of the intracellular region between homology domains III and IV. Cuts in the primary sequence here, but not between domains II and III, remove inactivation (113); antibodies to this region block inactivation (116); and mutations of lysine to asparagine residues in this region accelerate inactivation (92).

Certain transient $\mathrm{K}^{+}$channels display similar effects. Inactivation is nearly independent of voltage, which suggests a ball-and-chain model in which the ball binds at the internal mouth of the channel (128). Mutations at the amino terminus of the protein abolish inactivation $(2,56,57,59)$ and thus the amino terminus of the $\mathrm{K}^{+}$channel's single homology domain seems to act like the flap between domains III and IV of the $\mathrm{Na}^{+}$channel. Hoshi et al (57) have synthesized the peptide corresponding to the amino-terminal sequence and applied it to Shaker $\mathrm{K}^{+}$channels mutated to remove the amino-terminus inactivation flap. This soluble version of the flap still caused inactivation at concentrations in the micromolar range. One may hope that site-directed mutations will identify the receptive region for the flap; will the same region be found for $\mathrm{Na}^{+}, \mathrm{Ca}^{2+}$, and $\mathrm{K}^{+}$channels?

\section{Streaming Potentials}

In a streaming potential experiment, an osmotic pressure gradient $P_{\text {osm }}$ forces a water flux through open channels. The water flux drags permeant cations along, but anions remain behind, which leads to a charge separation and therefore to a potential difference across the membrane. This potential difference is most sensitively revealed as a change in reversal potential $V_{\text {str }}$ compared with the value in the absence of an osmotic pressure gradient. The number $N$ of water molecules associated with a single permeant cation is given by $N=\left(z \mathrm{FV}_{\text {str }}\right) /\left(\mathrm{W} P_{\text {osm }}\right)(75,103)$. The measurements are performed with the largest possible cation, so that it completely fills the pore; $N$ is then interpreted as the number of water molecules in front and back of the permeant ion, and it gives an idea about the length of the narrowest region. For the high-conductance $\mathrm{K}^{+}$channel, $N=2-3$, and the narrowest region of

the pore seems to be $<10 \AA$ long (86). The theory does not rule out the presence of several equally narrow regions within the same channel.

\section{Where and What are the Binding Sites?}

WHERE? Efforts are now under way in many laboratories to localize the binding sites described here. The simplest question is whether the various sites are $(a)$ within the membrane-spanning regions of the channel, or $(b)$ in 
the protrusions into the extracellular and intracellular space. The first possibility presumably applies to those sites that are sensitive to the membrane field. A slightly tilted $\alpha$-helix, with four amino-acid residues per turn, would have four or five turns exposed to the channel at intervals of about $5.4 \AA$. If each of these turns constitutes a distinct binding site for permeant or blocking cations, this would provide enough sites even to account for $\mathrm{K}^{+}$channels. The distance between turns is small enough to account for the postulated mutual repulsions included in several theories of permeation (72). The voltagedependent local anesthetic-binding sites are indeed within the M2 membrane spanning region of nicotinic receptors $(27,71)$. In this example, the site is composed of hydroxyl side chains, but cationic blockers of voltage-dependent channels might bind to carboxylate side chains.

Other information about the importance of the membrane regions alone comes from information on channel-forming peptides. Peptides have been synthesized that contain only the uncharged amino acids of the putative M2 membrane-spanning region from the Torpedo ACh receptor $\delta$ subunit, flanked by two positively and one negatively charged residues from the putative extramembrane regions. These peptides presumably form homo-oligomeric aggregates in the membrane. The resulting channels show cation selectivity (97). In another case, nonselective cation channels were formed from a 22-mer corresponding to the S3 region of the electrically excitable $\mathrm{Na}^{+}$ channel, including three flanking acidic groups (one of them poorly conserved) (98). Indeed, cation-selective channels are formed even if the peptides lack the flanking charged regions (69), thus favoring the membrane-spanning regions of the channel as binding sites. Two additional points, however, favor protrusions into the extracellular and intracellular space as binding sites. First, the putative extramembrane regions of channels have marked net charges (negative for most known cation channels). Second, the cation-selective nicotinic acetylcholine receptor channel is thought to be lined by the M2 helix, which is rich in hydroxyl-containing side chains. The homologous regions of the anion-selective GABA and glycine receptors are similar, which implies that charge selectivity occurs elsewhere.

Voltage-independent binding sites for cationic blockers could lie at the membrane surface or just a few residues away from it, like the three rings of charge identified in reference $58(1,2$, and 5 residues from the M2 region). Charybdotoxin binding is influenced by groups 5,10 , and 14 residues from the S5 helix, and 5 and 8 residues from the S6 helix $(76,79)$. One of these, threonine- 449 , also affects blockade by external TEA and single-channel conductance (81). The glu residue that influences TTX binding to a $\mathrm{Na}^{+}$ channel is 14 residues from the S6 helix (96). Many researchers now think that the S5-S6 loop actually lines the channel, but none of the sites thus far identified in this region is voltage-dependent. 
WHAT? There are two (perhaps overlapping) views on the nature of the binding sites. (a) The sites could be formed from individual amino-acid side chains that make highly specific contacts with permeant ions and with blocking molecules. $(b)$ The sites could be annuli whose properties are averaged from the four or five side chains projecting into the channel's lumen at a given depth. More specifically, one might ask how many subunits must contribute to a carboxylate or hydroxyl side chain to form a high-affinity binding site for $\mathrm{Ba}^{2+}$ within a $\mathrm{K}^{+}$channel? It is probably fruitless to approach such a question from first principles. Happily, the experimental approach to this questionand to many others presented in this chapter-using site-directed mutagenesis, is straightforward and now under way in several laboratories. Descriptions involving high-resolution structural techniques such as X-ray diffraction, however, are still several years away. When available, they will provide decisive tests for much of what has been deduced.

\section{ACKNOWLEDGMENTS}

I thank R. Aldrich and R. MacKinnon for sharing their work prior to publication, P. Lazarow for challenges on rectification, and N. Davidson, B. Hille, T. Begenisich, and members of my research group for many helpful comments. Preparation of this review was supported by grants from the Klingenstein Foundation, the Muscular Dystrophy Association, and the National Institutes of Health (GM-29836 and NS-11756).

\section{Literature Cited}

1. Adelman, W., French, R. L. 1978. Blocking of the squid axon potassium channel by caesium ions. J. Physiol. 276:13-25

2. Aldrich, R. W. 1990. Biophysical and molecular mechanisms of potassium channel gating. Biophys. J. 57:195a

3. Aldrich, R. W., Stevens, C. F. 1987. Voltage-dependent gating of single sodium channels from mammalian neuroblastoma cells. J. Neurosci. 7:41831

4. Almers, W. A., McCleskey, E. W. 1984. Non-selective conductance in calcium channels of frog muscle: calcium selectivity in a single-file pore. $J$. Physiol. 353:585-608

5. Anderson, C. A., Mackinnon, R., Smith, C., Miller, C. 1988. Charybdotoxin block of single $\mathrm{Ca}^{2+}$-activated $\mathrm{K}^{+}$ channels: Effects of channel gating, voltage, and ionic strength. J. Gen. Physiol. $91: 317-33$

6. Andersen, O. S. 1989. Kinetics of ion movement mediated by carriers and channels. Meth. Enzym. 171:62-112
7. Apell, H. J., Bamberg, E., Lauger, P. 1979. Effects of surface charge on the conductance of the gramicidin channel. Biochim. Biophys. Acta 552:369-78

8. Armstrong, C. M. 1966. Time course of $\mathrm{TEA}^{+}$-induced anomalous rectification in squid giant axons. J. Gen. Physiol. 50:491-503

9. Armstrong, C. M. 1971. Interaction of tetraethylammonium ion derivatives with the potassium channels of giant axons. J. Gen. Physiol 58:413-37

10. Armstrong, C. M., Bezanilla, F. 1977. Inactivation of the sodium channel. II. Gating current experiments. J. Gen. Physiol. 70:567-90

11. Armstrong, C. M., Binstock, L. 1965. Anomalous rectification in the squid giant axon injected with tetraethylammonium chloride. J. Gen. Physiol, 48: $859-72$

12. Armstrong, C. M., Croop, R. S. 1982. Simulation of Na channel inactivation by thiazin dyes. J. Gen. Physiol. 80:64162

13. Armstrong, C. M., Swenson, R. P., 
Taylor, S. 1982. Block of squid axon K channels by internally and externally applied barium ions. J. Gen. Physiol. 80:663-82

14. Armstrong, C. M., Taylor, S. R. 1980. Interaction of barium ions with potassium channels in squid giant axons. Biophys. J. 30:473-88

15. Begenisich, T. 1987. Molecular properties of ion permeation through sodium channels. Annu. Rev. Biophys. Biophys. Chem. 16:247-63

15a. Begenisich, T., Cahalan, M. 1980. Sodium channel permeation in squid axons. II: Non-independence and currentvoltage relations. J. Physiol. 307:24357

15b. Begenisich, T., Danke, M. 1983. Hydrogen ion block of the sodium pore in squid giant axons. J. Gen. Physiol. 82:599-618

16. Bell, J. E., Miller, C. 1984. Effects of phospholipid surface charge on ion conduction in the $\mathrm{K}^{+}$channel of sarcoplasmic reticulum. Biophys. J. 45:27988

17. Benham, C. D., Bolton, T. B., Lang, R. J., Takewaki, T, 1985. The mechanism of action of $\mathrm{Ba}^{2+}$ and TEA on single $\mathrm{Ca}^{2+}$-activated $\mathrm{K}^{+}$-channels in arterial and intestinal smooth muscle cell membranes. Pflügers Arch. 403:120-27

18. Bezanilla, F., Armstrong, C. M. 1972. Negative conductance caused by entry of sodium and cesium ion into the potassium channels of squid axons. J. Gen. Physiol. 60:588-608

19. Byerly, L., Chase, P. B., Stimers, J. R. 1985. Permeation and interaction of divalent cations in calcium channels of snail neurons. J. Gen. Physiol. 85:491518

20. Cahalan, M. D., Almers, W. 1979. Block of sodium conductance and gating current in squid giant axons poisoned with quaternary strychnine. Biophys. $J$. 27:57-74

21. Campbell, D. L., Rasmusson, R. L., Strauss, H. C. 1988. Theoretical study of the voltage and concentration-dependence of the anomalous mole fraction effect in single calcium channels - new insights into the characterization of multi-ion channels. Biophys. J. 54:94554

22. Carbone, E., Lux, H. D. 1988. Omegaconotoxin blockade distinguishes $\mathrm{Ca}$ from $\mathrm{Na}$ permeable states in neuronal calcium channels. Pflügers Arch. 413: 14-22

23. Catterall, W. A. 1980 . Neurotoxins that act on voltage-sensitive sodium channels in excitable membranes. Annu. Rev. Pharmacol. Toxicol. 20:15-43

24. Catterall, W. A. 1988. Structure and function of voltage-sensitive ion channels. Science 242:50-61

25. Cecchi, X., Wolff, D., Alvarez, O., Latorre, R. 1987. Mechanisms of $\mathrm{Cs}^{+}$ blockade in a $\mathrm{Ca}^{2+}$-activated $\mathrm{K}^{+}$channel from smooth muscle. Biophys. $J$. 52:707-16

26. Chabala, L. D., Andersen, O. S. 1988. Evidence for a net negative charge near the guanidinium toxin binding-site and the entrance to rat-brain sodium-channels. FASEB J. 2:534

27. Charnet, P., Labarca, C., Leonard, R. J., Vogelaar, N. J., Czyzyk, L., et al. 1990. An open-channel blocker interacts with adjacent turns of $\alpha$-helices in the nicotinic acetylcholine receptor. Neuron 4:87-95

28. Chesnoy-Marchais, D. 1985. Kinetic properties and selectivity of calciumpermeable single channels in Aplysia neurones. J. Physiol. 367:457-88

29. Cooper, E. C., Agnew, W. S. 1989. Reconstituted voltage-sensitive sodium channels from eel electroplax-activation of permeability by quaternary lidocaine, $\mathrm{N}$-bromoacetamide, and $\mathrm{N}$-bromosuccinimide. J. Membr. Biol. 111:253-64

30. Danko, M., Smith-Maxwell, C., McKinney, L., Begenisich, T. 1986. Block of sodium channels by internal mono- and divalent guanidinium analogues. Biophys. J. 49:509-19

31. DeCoursey, T. E., Chandy, K. G., Gupta, S., Cahalan, M. D. 1987. Two types of potassium channels in murine $\mathrm{T}$ lymphocytes. J. Gen. Physiol. 89:379404

32. Diebler, H., Eigen, M., Ilgenfritz, G., Maas, G., Winkler, R. 1969. Kinetics and mechanism of reactions of main group metal ions with biological carriers. Pure Appl. Chem. 20:93-115

33. Eaton, D. C., Brodwick, M. S. 1980. Effect of barium on the potassium conductance of squid axons. J. Gen. Physiol. 75:727-50

34. Eisenman, G., Dani, J. A. 1987. An introduction to molecular architecture and permeability of ion channels. Annu. Rev. Biophys. Biophys. Chem. 16:20526

35. Eisenman, G., Horn, R. 1983. Ionic selectivity revisited: the role of kinetic and equilibrium processes in ion permeation through channels. J. Memb. Biol. 76:197-225

36. Eisenman, G., Latorre, R., Miller, C. 1986. Multi-ion conduction and selectiv- 
ity in the high-conductance $\mathrm{Ca}^{2+}$-activated $\mathrm{K}^{+}$channel from skeletal muscle. Biophys. J. 50:1025-34

37. Frazier, D. T., Narahashi, T., Yamada, M. 1970. The site of the action and active form of local anesthetics. Experiments with quaternary compounds. J. Pharmacol. Exp. Ther. 171:45-51

38. French, R. J., Shoukimas, J. J. 1981. Blockage of squid axon potassium conductance by internal tetra- $\mathrm{N}$-alkylammonium ions of various sizes. Biophys. $J$. 34:271-91

39. French, R. J., Shoukimas, J. J. 1985. An ion's view of the potassium channel. The structure of the permeation pathway as sensed by a variety of blocking ions. J. Gen. Physiol. 85:669-98

40. Friel, D, D., Tsien, R. W. 1989. Voltage-gated calcium channels: direct observation of the anomalous mole fraction effect at the single-channel level. Proc. Natl. Acad. Sci. USA 86:5207-11

41. Garnier, D., Rougier, O., Gargouil, Y. M., Coraboeuf, E. 1969. Analyse electrophysiologique du plateau des responses myocardiques: Mise en evidence d'un courant lent entrant en absence d'ions bivalents. Pflügers Arch. 313:321-42

42. Gordon, D., Merrick, D., Wollner, D. A., Catterall, W. A. 1988. Biochemical properties of sodium channels in a wide range of excitable tissues studied with site-directed antibodies. Biochemistry 27:7032-38

43. Green, W. N., Weiss, L. B., Andersen, O. S. 1987. Batrachotoxin-modified sodium channels in planar lipid bilayers. J. Gen. Physiol. 89:841-72

44. Greenblatt, R., Blatt, Y., Montal, M. 1985. The structure of the voltagesensitive sodium channel. Inferences derived from computer-aided analysis of the Electrophorus electricus channel primary structure. FEBS Lett. 193:125-34

45. Grissmer, S., Cahalan, M. 1989. TEA prevents inactivation while blocking open $\mathrm{K}^{+}$channels in human $\mathrm{T}$ lymphocytes. Biophys. J. 55:203-6

46. Guy, H. R. 1989. Models of voltageand transmitter activated membrane channels based on their amino acid sequences, In Monovalent Cations in Biological Systems, ed. C. A. Pasternak, pp. 32-58. Cleveland: CRC 32-58

47. Guy, H., Seetharamulu, P. 1986. Molecular model of the action potential sodium channel. Proc. Natl. Acad. Sci. USA 83:508-12

48. Hagiwara, S. 1983. In Membrane Potential-Dependent Ion Channels in
Cell Membrane. Phylogenetic and Developmental Approaches, pp. 70-75. New York: Raven

49. Hescheler, J., Pelzer, D., Trube, G., Trautwein, W. 1982. Does the organic calcium channel blocker D600 act from inside or outside on the cardiac cell membrane. Pflügers Arch. 393:287-91

50. Hess, P., Tsien, R. W. 1984. Mechanism of ion permeation through calcium channels. Nature 309:453-56

51. Hille, B. 1975. Ionic selectivity of $\mathrm{Na}$ and $K$ channels of nerve membranes. In Membranes: A series of advances, Lipid bilayers and biological membranes: $d y$ namic properties, ed. G. Eisenman, 3:255-323. New York: Dekker

52. Hille, B. 1977. Local anesthetics: hydrophilic and hydrophobic pathways for the drug-receptor reaction. J. Gen. Physiol. 69:497-515.

53. Hille, B. 1984. In Ionic Channels in Excitable Membranes. Sunderland, MA: Sinauer

54. Hondeghem, L. M., Katzung, B. G. 1977. Time- and voltage-dependent interactions of antiarrhythmic drugs with cardiac sodium channels. Biochim. Biophys. Acta 472:373-98

55. Hondeghem, L. M., Katzung, B. G. 1984. Antiarrhythmic agents: the modulated receptor mechanism of action of sodium and calcium channel-blocking drugs. Annu. Rev. Pharmacol. Toxicol. 24:387-423

56. Hoshi, T., Zagotta, W. N., Aldrich, R. W. 1989. Mutations in the amino terminal variable domain alter inactivation of Shaker B potassium channels in Xenopus oocytes. Soc. Neurosci. Abstr. 15: 338

57. Hoshi, T., Zagotta, W. N., Aldrich, R. W. 1990. A synthetic peptide with Shaker $B$ sequence restores inactivation in mutant channels that do not inactivate. Soc. Neurosci. Abstr. 16:4

58. Imoto, K., Busch, C., Sakmann, B., Mishina, M., Konno, T., et al. 1988 . Rings of negatively charged amino acids determine the acetylcholine receptor channel conductance. Nature 335:64548

59. Isacoff, E. Y., Jan, Y. N., Jan, L. Y. 1990. Structure-function studies on the Shaker $\mathrm{K}^{+}$channel. Biophys. J. 57:209a

60. James, W. M., Agnew, W. S. 1987. Multiple oligosaccharide chains in the voltage-sensitive $\mathrm{Na}$ channel from Electrophorus electricus: evidence for $\alpha$ 2,8-linked polysialic acid. Biochem. Biophys. Res. Comm. 148:817-26

61. Deleted in proof 
62. Khodorov, B. I. 1985. Batrachotoxin as a tool to study voltage-sensitive sodium channels of excitable membranes. Prog. Biophys. Mol. Biol. 45:57-148

63. Kostyuk, P. G., Mironov, S. L. 1986. Some predictions concerning the calcium channel model with different conformal states. Gen. Physiol. Biophys. 6:649-59

64. Kostyuk, P. G., Mironov, S. L. Shuba, Y. M. 1983. Two ion-selecting filters in the calcium channel of the somatic membrane of mollusc neurons. J. Membr. Biol. 76:83-93

65. Krueger, B. K., Worley, J. F. III, French, R. J. 1986. Block of sodium channels in planar lipid bilayers by guanidinium toxins and calcium. Ann. NY Acad. Sci. 479:257-68

66. Lansman, J. B. 1990. Blockade of current through single calcium channels by trivalent lanthanide cations. J. Gen. Physiol. 95:679-96

67. Lansman, J. B., Hess, P., Tsien, R. W. 1986. Blockade of current through single calcium channels by $\mathrm{Cd}^{2+}, \mathrm{Mg}^{2+}$, and $\mathrm{Ca}^{2+}$ : Voltage and concentration dependence of calcium entry into the pore. J. Gen. Physiol. 88:321-47

68. Latorre, R., Miller, C. 1983. Conduction and selectivity in potassium channels. J. Memb. Biol. 71:11-30

69. Lear, J. D., Wasserman, Z. R., DeGrado, W. F. 1988. Synthetic amphiphilic peptide models for protein ion channels. Science 240:1177-81

70. Leblanc, N., Hume, J. R. 1989. D 600 block of L-type $\mathrm{Ca}^{2+}$ channel in vascular smooth muscle cells: comparison with permanently charges derivitive, $D$ 890. Am. J. Physiol. 257:C689-95

71. Leonard, R. J., Labarca, C., Charnet, P., Davidson, N., Lester, H. A. 1988. Evidence that the M2 membranespanning region lines the ion channel pore of the nicotinic receptor. Science 242:1578-81

72. Levitt, D. G. 1978. Electrostatic calculations for an ion channel. II. Kinetic behavior of the gramicidin A channel. Biophys. J. 22:221-48

73. Levitt, D. G. 1984. Kinetics of movement in narrow channels. Curr. Top. Membr. Trans. 21:181-197

74. Levitt, D. G. 1986. Interpretation of biological ion channel flux data- reaction-rate versus continuum theory. Annu. Rev. Biophys. Biophys. Chem. 15:29-57

75. Levitt, D. G., Ellias, S. R., Hautman, J. M. 1978. Number of water molecules coupled to the transport of sodium, potassium and hydrogen ions via grami- cidin, nonactin or valinomycin. Biochim. Biophys. Acta 512:436-51

76. MacKinnon, R., Heginbotham, L., Abramson, T. 1990. Mapping the receptor site for a pore-blocking potassium channel inhibitor. Neuron. In press

77. MacKinnon, R., Latorre, R., Miller, C. 1989. Role of surface electrostatics in the operation of a high-conductance $\mathrm{Ca}^{2+}$-activated $\mathrm{K}^{+}$channel. Biochemistry 28:8092-99

78. MacKinnon, R., Miller, C. 1988. Mechanism of charybdotoxin inhibition of $\mathrm{Ca}^{++}$-dependent $\mathrm{K}^{+}$channels. Specific competition by $\mathrm{K}^{+}$.J. Gen. Physiol. 91:335-49

79. MacKinnon, R., Miller, C. 1989. Mutant potassium channels with altered binding of charybdotoxin, a pore-blocking peptide inhibitor. Science 245: $1382-85$

80. Mackinnon, R., Miller, C. 1989. Functional modification of a $\mathrm{Ca}^{2+}$-activated $\mathrm{K}^{+}$channel by trimethyloxonium. Biochemistry 28:8087-92

81. MacKinnon, R., Yellen, G. 1990. Mutations affecting blockade and ion permeation in voltage-activated potassium channels. Science. 250:276-79

82. Marban, E., Yue, D. T. 1989. Ion permeation in L-type Ca channels: evidence for triple-ion occupancy in the conduction pathway. Biophys. J. 55:594a

83. Matsuda, H. 1986. Sodium conductance of calcium channels of guinea pig ventricular cells induced by removal of external calcium ions. Pflügers Arch. 407:465-75

84. McDonald, T. F., Cavalie, A., Trautwein, W., Pelzer, D. 1986. Voltagedependent properties of macroscopic and elementary calcium channel currents in guinea pig ventricular myocytes. Pflügers Arch. 406:437-48

85. McLaughlin, S. 1989. The electrostatic properties of membranes. Annu. Rev. Biophys. Biophys. Chem. 18:113-36

86. Miller, C. 1982. Bis-quaternary ammonium blockers as structural probes of the sarcoplasmic reticulum $\mathrm{K}^{+}$channel. $J$. Gen. Physiol. 79:869-91

87. Miller, C., Latorre, R., Reisin, I. 1987. Coupling of voltage-dependent gating and $\mathrm{Ba}^{++}$block in the high conductance, $\mathrm{Ca}^{++}$-activated $\mathrm{K}^{+}$channel. J. Gen. Physiol. 90:427-49

88. Mironov, S. L. 1988. In Calcium and Ion Channel Modulation. ed. A. D. Grinnell, A. Armstrong, M. B. Jackson, pp. 43-51. New York: Plenum

89. Moczydlowski, E., Alvarez, O., Vergara, C., Latorre, R. 1985. Role of surface electrostatics in the operation of a 
high-conductance $\mathrm{Ca}^{2+}$-activated $\mathrm{K}^{+}$ channel. J. Membr. Biol. 83:273-82

90. Moczydlowski, E., Garber, S. S., Miller, C. 1984. Batrachotoxin-activated $\mathrm{Na}^{+}$channels in planar lipid bilayers. $J$. Gen. Physiol. 84:665-86

91. Moczydlowski, E., Hall, S., Garber, S. S., Strichartz, G., Miller, C. 1984. Voltage-dependent blockade of muscle $\mathrm{Na}^{+}$ channels by guanidinium toxins. J. Gen. Physiol. 84:687-704

92. Moorman, J. R., Joho, R. H., Kirsch, G. E., Brown, A. M. 1990. Point mutations in the region linking domains II and III which speed inactivation of $\mathrm{Na}$ currents. Biophys J. 57:296a

93. Nelson, M. T., French, R. J., Krueger, B. K. 1984. Voltage-dependent calcium channels from brain incorporated into planar lipid bilayers. Nature 308:77-81

94. Neyton, J., Miller, C. 1988. Discrete $\mathrm{Ba}^{2+}$ block as a probe of ion occupancy and pore structure in the high-conductance $\mathrm{Ca}^{2+}$-activated $\mathrm{K}^{+}$channel. $J$. Gen. Physiol. 92:569-86

95. Neyton, J., Miller, C. 1988. Potassium blocks barium permeation through a calcium-activated potassium channel. $J$. Gen. Physiol. 92:549-67

96. Noda, M., Suzuki, H., Numa, S., Stuhmer, W. 1989. A single point mutation confers tctrodotoxin and saxitoxin insensitivity on the sodium channel II. FEBS Lett. 259:213-16

97. Oiki, S., Danho, W., Madison, V., Montal, M. 1988. M2 $\delta$, a candidate for the structure lining the ionic channel of the nicotinic cholinergic receptor. Proc. Natl. Acad. Sci. USA 85:8703-7

98. Oiki, S., Danho, W., Montal, M. 1988. Channel protein engineering: synthetic 22-mer peptide from the primary structure of the voltage-sensitive sodium channel forms ionic channels in lipid bilayers. Proc. Natl. Acad. Sci. USA 85:2393-97

99. Pelzer, D., Trautwein, W., McDonald, T. F. 1982. Calcium channel block and recovery from block in mammalian ventricular muscle treated with organic channel inhibitors. Pflügers Arch. 394: 97-105

100. Pietrobon, D., Prod'hom, B., Hess, P. 1988. Conformational changes associated with ion permeation in L-type calcium channels. Nature 333:373-76

101. Prod'hom, B., Pietrobon, D., Hess, P. 1987. Direct measurements of proton transfer rates to a group controlling the dihydropyridine-sensitive $\mathrm{Ca}^{2+}$ channel. Nature 329:243-46

102. Pusch, M., Conti, F., Stuhmer, W. 1989. Intracellular magnesium blocks sodium outward currents in a voltagedependent and dose-dependent manner. Biophys. J. 55:1267-71

103. Rosenberg, P. A., Finkelstein, A. 1978. Interaction of ions and water in gramicidin A channels: Streaming potentials across lipid bilayer membranes. J. Gen. Physiol. 72:327-40

104. Shapiro, B. I. 1977. Effects of strychnine on the sodium conductance of the frog node of Ranvier. J. Gen. Physiol. 69:915-26

105. Sigworth, F. J., Spalding, B. C. 1980. Chemical modification reduce the conductance of sodium channels in nerve. Nature 283:293-95

105a. Smith-Maxwell, C., Begenisich, T. 1987. Guadidium analogues as probes of the squid axon sodium pore. Evidence for internal surface charges. J. Gen. Physiol. 90:361-74

106. Spalding, B. C. 1980. Properties of toxin-resistant sodium channels produced by chemical modification in frog skeletal muscle. J. Physiol. 305:485-500

107. Spruce, A. E., Standen, N. B., Stanfield, P. R. 1987. The action of external tetraethylammonium ions on unitary delayed rectifier potassium channels of frog skeletal muscle. J. Physiol. 393: $467-78$

108. Standen, N. B., Stanfield, P. R., Ward, T. A. 1985. Properties of single potassium channels in vesicles formed from the sarcolemma of frog skeletal muscle. J. Physiol. 364:339-58

109. Stanfield, P. R. 1983. Tetraethylammonium ions and the potassium permeability of excitable cells. Rev. Physiol. Biochem. Pharmacol. 97:1-67

110. Starmer, C. F., Courtney, K. R. 1986. Modeling ion channel blockade at guarded binding sites: application to tertiary drugs. Am. J. Physiol. 251:H84856

111. Strichartz, G. R. 1973. The inhibition of sodium currents in myelinated nerve of quaternary ammonium derivatives of lidocaine. J. Gen. Physiol. 62:35-37

112. Strichartz, G. R., Rando, T., Wang, G. K. 1987. An integrated view of the molecular toxinology of sodium channel gating in excitable cells. Annu. Rev. Neurosci. 10:237-67

113. Stuhmer, W., Conti, F., Suzuki, H., Wang, X., Noda, M., et al. 1989. Structural parts involved in activation of the sodium channel. Nature 339:597603

114. Thomsen, W. J., Catterall, W. A. 1989. Localization of the receptor site for $\alpha$ scorpion toxins by antibody mapping: implications for sodium channel topolo- 
496 LESTER

gy. Proc. Natl. Acad. Sci. USA 86: 10161

115. Tsien, R. W., Hess, P., McCleskey, E. W., Rosenberg, R. L. 1987. Calcium channels-mechanisms of selectivity, permeation, and block. Annu. Rev. Biophys. Biophys. Chem. 16:265-90

116. Vassilev, P., Scheuer, T., Catterall, W. A. 1989. Inhibition of inactivation of single sodium channels by a site-directed antibody. Proc. Natl. Acad. Sci. USA $86: 8147-51$

117. Vergara, C., Latorre, R. 1983. Kinetics of $\mathrm{Ca}^{2+}$-activated $\mathrm{K}^{+}$channels from rabbit muscle incorporated into planar bilayers. J. Gen. Physiol. 82:543-68

118. Villarroel, A., Alvarez, O., Oberhauser, A., Latorre, R. 1988. Probing a $\mathrm{Ca}^{2+}$. activated $\mathrm{K}^{+}$channel with quaternary ammonium ions. Pflügers Arch. 413: 118-26

119. Weiss, R. E., Horn, R. 1986. Functional differences between two classes of sodium channels in developing rat skeletal muscle. Science 233:361-64

120. Winegar, B., Kelly, R., Lansman, J. B. 1990. Block of single calcium channels in $\mathrm{C} 2$ myotubes by $\mathrm{Zn}, \mathrm{Fe}, \mathrm{Co}$, and $\mathrm{Ni}$. Biophys. J. 57:525a

121. Woodhull, A. M. 1973. Ionic blockage of sodium channels in nerve. J. Gen. Physiol. 61:687-708
122. Worley, J. F. III, Fiener, L. A., Jones, L., Nelson, M. T. 1986. Different types of calcium channels incorporated into planar lipid bilayers. Biophys. J. 49: $176 \mathrm{a}$

123. Worley, J. F. III, French, R. J., Krueger, B. K. 1986. Trimethyloxonium modification of single batrachotoxinactivated sodium channel in planar bilayers. J. Gen. Physiol. 87:327-49

124. Yeh, J. Z., Narahashi, T. 1977. Kinetic analysis of pancuronium interaction with sodium channels in squid axon membranes. J. Gen. Physiol. 69:293-323

125. Yellen, G. 1984. Ionic permeation and blockade in $\mathrm{Ca}^{2+}$-activated $\mathrm{K}^{+}$channels of bovine chromaffin cells. J. Gen. Physiol. 84:157-86

126. Yellen, G. 1984. Relief of $\mathrm{Na}^{+}$block of $\mathrm{Ca}^{2+}$-activated $\mathrm{K}^{+}$channels by external cations. J. Gen. Physiol. 84:187-99

127. Yellen, G. 1987. Permeation in potassium channels: implications for channel structure. Annu. Rev. Biophys. Biophys. Chem. 16:227-46

128. Zagotta, W. N., Hoshi, T., Aldrich, R. W. 1989. Gating of single Shaker $\mathrm{K}^{+}$ channels in Drosophila muscle and in Xenopus oocytes injected with Shaker mRNA. Proc. Natl. Acad. Sci. USA 86:7243-47 
$\bar{A}$ Annual Review of Physiology

Volume 53, 1991

\section{CONTENTS}

\section{Perspectives}

Excitation-Contraction Coupling and the Mechanism of Muscle Contraction, Setsuro Ebashi

ENDOCRINOLOGY

Daryl K. Granner, Section Editor

Thyroid Hormone Regulation of Gene Expression, Gregory A.

Brent, David D. Moore, and P. Reed Larsen

Receptor G Protein Signaling in Yeast, Kendall J. Blumer and Jeremy Thorner

Comparative Physiology

Donald C. Jackson, Section Editor

Adaptations to Hypoxia in Birds: How to Fly High, Frank $M$. Faraci

Interactions Between Hypoxia and Hypothermia, Stephen C. Wood

Intermittent Breathing in Vertebrates, W. K. Milsom

Ontogeny of Cardiovascular and Respiratory Physiology of

Lower Vertebrates, Warren W. Burggren and Alan W. Pinder

See also

$\beta$-Adrenergic Receptor Regulation

Controls of Myogenesis

Regulators of Angiogenesis

Regulation of Surfactant Synthesis

Cardiovascular Physiology

Howard E. Morgan, Section Editor

$\beta$-Adrenergic Receptor Regulation in the Heart in

Pathophysiologic States: Abnormal Adrenergic

Responsiveness, Charles J. Homcy, Stephen F. Vatner, and Dorothy E. Vatner 
Control of Growth and Differentiation of Vascular Cells by Extracellular Matrix Proteins, David J. Carey

Growth Factors, Proto-Oncogenes, and Plasticity of the Cardiac Phenotype, Thomas G. Parker and Michael D. Schneider

Hormones, Growth Factors, and Myogenic Differentiation, James R. Florini, Daina Z. Ewton, and Karen A. Magri

Regulators of Angiogenesis, Michael Klagsbrun and Patricia A. D'Amore

See also

Excitation and Contraction

Gene Regulation by T3

Measurement of Cellular Magnesium

Magnesium Transport

Cytosolic Free Magnesium 273

Mg Gating of the Inward Rectifier 289

Magnesium and Cardiac Channels

Permeation at Voltage-Gated Channels

Adrenergic Receptor Regulation

Calcium Pump

Structure-Function of $\mathrm{Na}$, K-ATPase

\section{Cellular and Molecular Physiology}

Paul De Weer, Section Editor

Methods for Measurement of Intracellular Magnesium: NMR and Fluorescence, Robert E. London

Mechanisms of Magnesium Transport, Peter W. Flatman

Cellular Magnesium and $\mathrm{Na} / \mathrm{Mg}$ Exchange in Heart Cells, Elizabeth Murphy, Craig C. Freudenrich, and Melvyn Lieberman

Magnesium Gating of the Inwardly Rectifying $\mathrm{K}^{+}$Channel, Hiroko Matsuda

Modulation of Cardiac Ion Channels by Magnesium, Z. S. Agus and M. Morad

Calmodulin Mutants and $\mathrm{Ca}^{2+}$-Dependent Channels in Paramecium, Robin R. Preston, John A. Kink, Robert D. Hinrichsen, Yoshiro Saimi, and Ching Kung 
See also

Gene Regulation by T3

Receptors and G Proteins of Yeast 37

Vascular ECM

Myocardial Growth Factors

Controls of Myogenesis

Ion Channels in Colon

Ion Channel Surface Charges

Ion Transport in Gallbladder

Surfactant Protein Structure

Intracellular Surfactant Metabolism

Hair Cells

Permeation at Voltage-Gated Channels

Adrenergic Receptor Regulation

Epithelial $\mathrm{Na}^{+}$Channels

Calcium Pump

Anion Exchanger Gene Family

Structure-Function of Na, K-ATPase

Actin Assembly and Cell Motility

Microtubule-Based Motility

Myosin-I

Gastrointestinal Physiology

Gearge Sachs, Section Editor

Ion Channels and Colonic Salt Transport, David C. Dawson

Surface Charges and Ion Channel Functions, William N. Green and Olaf $S$. Andersen

Regulation of Ion Transport Across Gallbladder Epithelium, Luis Reuss, Yoav Segal, and Guillermo Altenberg

See also

Receptors and G Proteins of Yeast

$\mathrm{Mg}$ Gating of the Inward Rectifier

Permeation at Voltage-Gated Channels

Epithelial $\mathrm{Na}^{+}$Channels

Calcium Pump

Anion Exchanger Gene Family

Structure-Function of Na, K-ATPase

Microtubule-Based Motility 


\section{Respiratory Physiology}

John A. Clements, Section Editor

Structure and Properties of the Surfactant-Associated Proteins,

Samuel Hawgood and Kathleen Shiffer

Regulation of Pulmonary Surfactant Secretion and Clearance, Jo Rae Wright and Leland G. Dobbs

Hormonal Control of Surfactant System in Fetal Lung, Carole

$R$. Mendelson and Vijayakumar Boggaram

Synthesis and Assembly of Lung Surfactant, Henk

P. Haagsman and Lambert M. G. van Golde

See also

Receptors and G Proteins of Yeast

Measurement of Cellular Magnesium

Adrenergic Receptor Regulation

Epithelial $\mathrm{Na}^{+}$Channels

Calcium Pump

NEUROPHYSIOLOGY

Arthur M. Brown, Section Editor

The Electrophysiology of Hair Cells, Jonathan F. Ashmore

Strategies for Studying Permeation at Voltage-Gated Ion

Channels, Henry A. Lester

Regulation of Adrenergic Receptor Responsiveness Through Modulation of Receptor Gene Expression, Sheila Collins, Marc G. Caron, and Robert J. Lefkowitz

See also

Receptors and G Proteins of Yeast

$\beta$-Adrenergic Receptor Regulation

$\mathrm{Mg}$ Gating of the Inward Rectifier

Magnesium and Cardiac Channels

Ion Channel Surface Charges

Renal and Electrolyte Physiology

Erich E. Windhager, Section Editor

Epithelial $\mathrm{Na}^{+}$Channels, $P . R$. Smith and D. J. Benos

The Calcium Pumping ATPase of the Plasma Membrane,

Ernesto Carafoli

The Band 3-Related Anion Exchanger (AE) Gene Family,

Seth L. Alper 
Structure-Function Relationship of the Na, K-ATPase,

Jean-Daniel Horisberger, Victor Lemas, Jean-Pierre

Kraehenbühl, and Bernard C. Rossier

See also

Ion Channels in Colon

321

Ion Channel Surface Charges 341

Ion Transport in Gallbladder $\quad 361$

SPECIAL TOPIC: MOTILITY

Michael P. Sheetz, Special Topic Editor

The Role of Actin Polymerization in Cell Motility, John A. Cooper

Genetic Alteration of Proteins in Actin-Based Motility Systems, G. Gerisch, A. A. Noegel, and M. Schleicher

Functions of Microtubule-Based Motors, Trina A. Schroer and Michael P. Sheetz

Myosin-I, Thomas D. Pollard, Stephen K. Doberstein, and Henry G. Zot

INDEXES

Subject Index

Cumulative Index of Contributing Authors, Volumes 49-53

698

Cumulative Index of Chapter Titles, Volumes 49-53

701 